\title{
Overdiagnosis of asthma in obese and nonobese adults
}

\author{
Shawn D. Aaron MD, Katherine L. Vandemheen BScN, Louis-Philippe Boulet MD, \\ R. Andrew Mclvor MD, J. Mark FitzGerald MD, Paul Hernandez MD, Catherine Lemiere MD, \\ Sat Sharma MD, Stephen K. Field MD, Gonzalo G. Alvarez MD, Robert E. Dales MD, \\ Steve Doucette MSc, Dean Fergusson PhD, for the Canadian Respiratory Clinical Research Consortium
}

\section{ABSTRACT}

Background: It is unclear whether asthma is overdiagnosed in developed countries, particularly among obese individuals, who may be more likely than nonobese people to experience dyspnea.

Methods: We conducted a longitudinal study involving nonobese (body mass index 20-25) and obese (body mass index $\geq 30$ ) individuals with asthma that had been diagnosed by a physician. Participants were recruited from 8 Canadian cities by means of random-digit dialing. A diagnosis of current asthma was excluded in those who did not have evidence of acute worsening of asthma symptoms, reversible airflow obstruction or bronchial hyperresponsiveness, despite being weaned off asthma medications. We stopped asthma medications in those in whom a diagnosis of asthma was excluded and assessed their clinical outcomes over 6 months.

Results: Of 540 individuals with physician-diagnosed asthma who participated in the study, 496 (242 obese and 254 nonobese) could be conclusively assessed for a diagnosis of asthma. Asthma was ultimately excluded in 31.8\% (95\% confidence interval $[\mathrm{Cl}] 26.3 \%-37.9 \%$ ) in the obese group and in $28.7 \%(95 \% \mathrm{Cl} 23.5 \%-34.6 \%)$ in the nonobese group. Overdiagnosis of asthma was no more likely to occur among obese individuals than among nonobese individuals $(p=0.46)$. Of those in whom asthma was excluded, $65.5 \%$ did not need to take asthma medication or seek health care services because of asthma symptoms during a 6-month follow-up period.

Interpretation: About one-third of obese and nonobese individuals with physician-diagnosed asthma did not have asthma when objectively assessed. This finding suggests that, in developed countries such as Canada, asthma is overdiagnosed.

Une version française de ce résumé est disponible à l'adresse www.cmaj.ca/cgi/content/full/179/11/1121/DC1

CMAJ 2008;179(11):1121-31

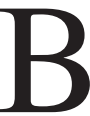
etween 1980 and 1994, the age-adjusted prevalence of asthma increased by $75 \%$ in Canada and the United States. ${ }^{1,2}$ The prevalence of both the symptoms and diagnosis of asthma may depend heavily on an awareness of asthma in the population studied. ${ }^{3}$ In recent decades, awareness of asthma has increased significantly among patients and their physicians. Part of this awareness has been stimulated by the medical community and part by the pharmaceutical industry, which has developed new medications for asthma and has directly or indirectly advertised these medications to patients and health care providers. ${ }^{3}$ In Scotland, the proportion of children reporting asthma symptoms who received a diagnosis of asthma from their physicians increased from $28 \%$ in 1964 to $64 \%$ in $1999 .{ }^{4}$ Part of the increase in prevalence may be attributable to changes in diagnostic labelling.

Over the past 3 decades, the incidence and prevalence of obesity has increased concurrently with the incidence and prevalence of asthma, which indicates a possible link between obesity and asthma. ${ }^{5-7}$ Studies have suggested that asthma is almost twice as likely to be diagnosed in obese people as in nonobese people. In Canada and the United States, 8.8\%$9.2 \%$ of obese adults reported having received a diagnosis of asthma from a physician, as compared with $4 \%-5 \%$ of nonobese adults. ${ }^{8,9}$

It is unclear whether this increased tendency to diagnose asthma in patients with respiratory symptoms is appropriate, or whether asthma may be overdiagnosed in developed countries. Potential overdiagnosis of asthma may be even more pronounced among obese people. Obesity decreases chest wall compliance, which results in reduced lung volumes, increased work of breathing and increased energy and oxygen costs of breathing. ${ }^{10-12}$ Because obese patients report more dyspnea and asthma-like symptoms than nonobese patients, they may be more likely to be misdiagnosed by their physicians as having asthma.

We conducted this study to determine the proportion of obese and nonobese Canadian adults who have an incorrect diagnosis of asthma. We also assessed whether overdiagnosis of asthma was more prevalent among obese than among nonobese individuals. Finally, we determined what proportion of obese and nonobese patients could safely discontinue their asthma medications once a diagnosis of asthma was excluded.

From the Ottawa Health Research Institute (Aaron, Vandemheen, Alvarez Dales, Doucette, Fergusson), University of Ottawa, Ottawa, Ont.; the Centre de recherche (Boulet), Hôpital Laval, Université Laval, Laval, Que.; the Firestone Institute for Respiratory Health (Mclvor), McMaster University, Hamilton, Ont.; the Department of Medicine (Fitzgerald), University of British Columbia, Vancouver, BC; the Department of Medicine (Hernandez) Dalhousie University, Halifax, NS; the Department of Medicine (Lemiere), Université de Montréal, Montréal, Que.; the Department of Medicine (Sharma), University of Manitoba, Winnipeg, Man.; and the Department of Medicine (Field), University of Calgary, Calgary, Alta. 


\section{Methods}

\section{Study population}

We recruited study participants from December 2005 to December 2007 via random-digit dialing using a geographically stratified general population with phone lines. ${ }^{13}$ We randomly sampled potential participants from 8 cities distributed geographically across Canada (Vancouver, Calgary, Winnipeg, Hamilton, Ottawa, Montréal, Québec and Halifax) and from surrounding rural areas. Within each geographic region, area

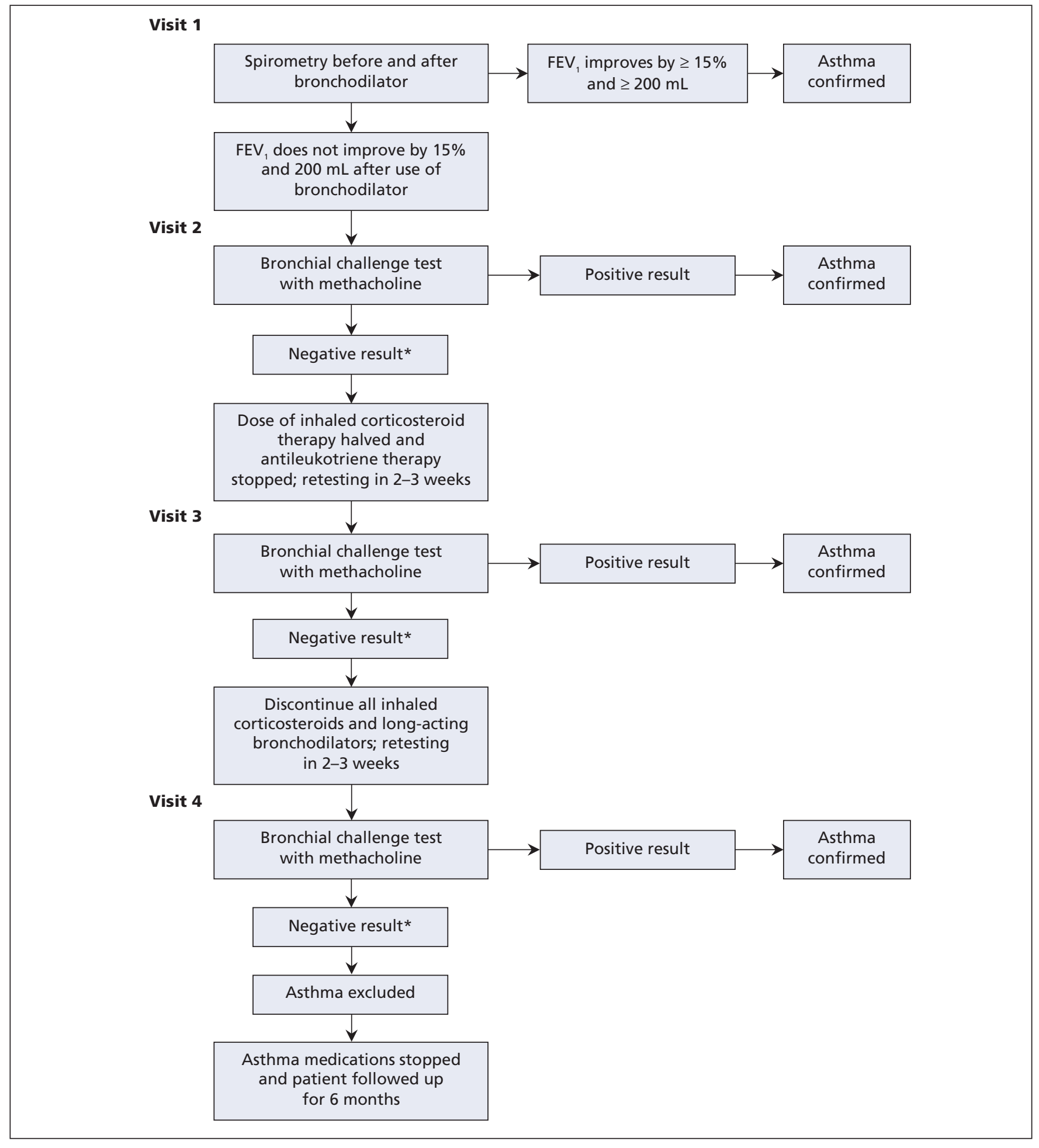

Figure 1: Algorithm used for serial testing to confirm or exclude asthma in participants using inhaled corticosteroids or leukotriene receptor antagonists on entry into the study. *Negative result of bronchial challenge test $=$ the dose of methacholine at which the forced expiratory volume in 1 second $\left(\mathrm{FEV}_{1}\right)$ fell by at least $20 \%$ was greater than $8 \mathrm{mg} / \mathrm{mL}$. 
codes were assigned based on their weight to one or more of the sampling regions. The target population included household residents in these cities as well as rural and suburban residents whose telephone exchanges were known to be located within 90 minutes' drive of each of the 8 metropolitan areas. For the urban, suburban and semirural subpopulations within Canada, telephone coverage is almost universal (with the exception of the very poor and transient groups). Thus, our sampling technique was meant to approximate a true random sample of the Canadian population with asthma.

Potential respondents were contacted by telephone and briefly introduced to the study. They were then asked the following question via a recorded message from the local study coordinator: "Is there a member of your household aged 16 years of age or older who has been diagnosed with asthma?" If the person answered Yes, the study assistant contacted the identified person with asthma directly. Those contacted who stated that they had current asthma diagnosed by a physician and who met the other screening criteria for eligibility were invited to the local study centre for a complete eligibility assessment and entry into the study. The study was approved by the research ethics boards of the 8 participating study hospitals. All patients who participated in the study gave written informed consent.

We included people who (a) were at least 16 years old, (b) had current asthma diagnosed by a physician, and (c) were either normal body weight (body mass index 20-25) or obese (body mass index $\geq 30$ ). We excluded overweight patients (body mass index 25-30) because we wanted a clear physiologic distinction between the 2 study groups. We also excluded patients who (a) were taking long-term oral corticosteroid therapy; (b) could not undergo a bronchial challenge test because of a history of myocardial infarction or stroke within the 3 months before the study or because of known aortic or cerebral aneurysms, ${ }^{14}$ (c) had a history of smoking of more than 10 cigarette pack-years (to exclude patients with possible chronic obstructive pulmonary disease); (d) were unable or unwilling to provide informed consent; or (e) were unable to undergo spirometry.

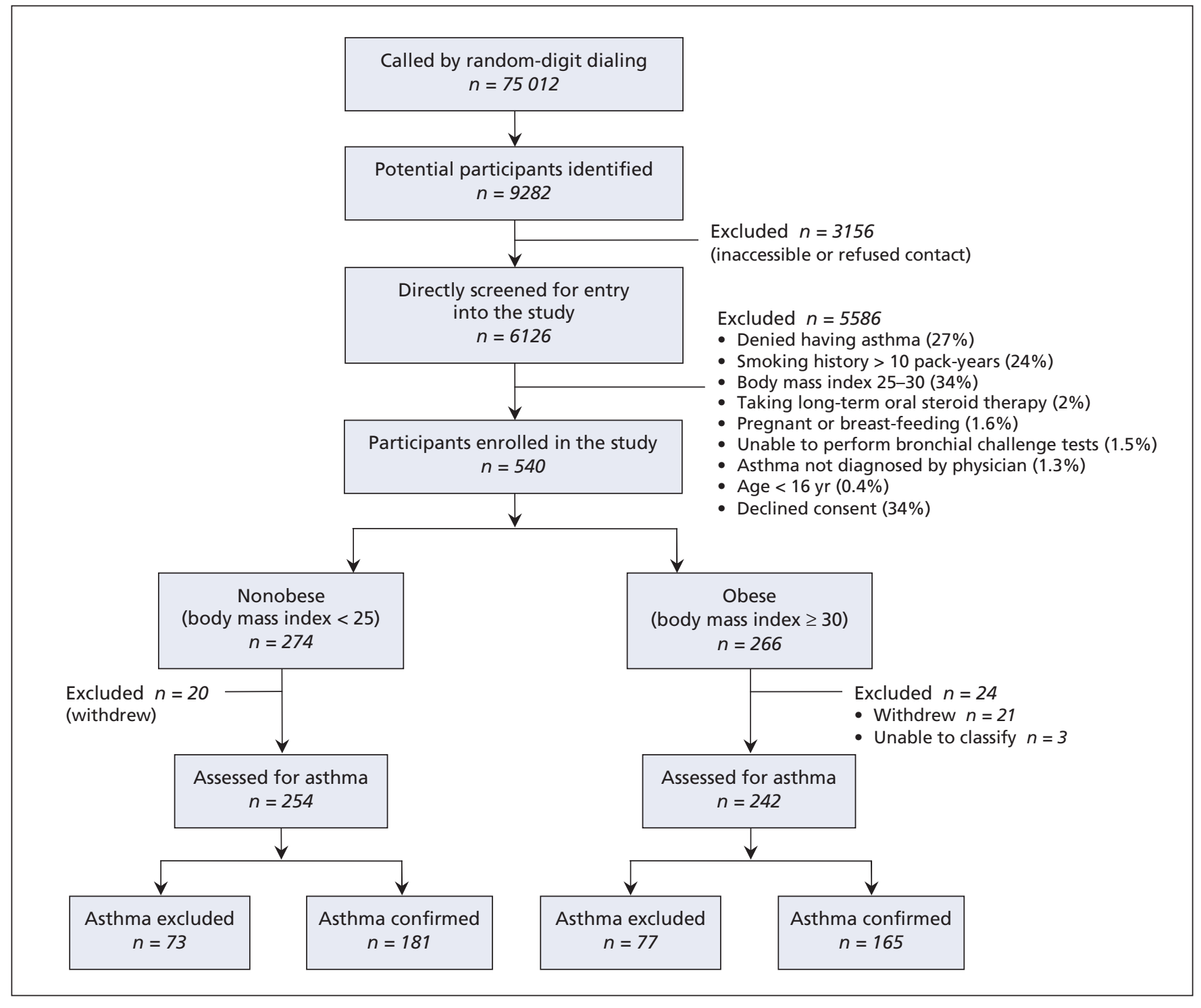

Figure 2: Selection of participants and study outcomes. 


\section{Primary outcome}

The primary outcome was the percentage of participants in the obese and nonobese groups in whom the diagnosis of asthma was excluded after a complete objective assessment. The diagnosis was excluded if there was no evidence of acute worsening of asthma symptoms, reversible airflow obstruction or bronchial hyperresponsiveness, despite being weaned off asthma medications.

\section{Asthma assessment}

On entry to the study, participants had their height, weight and waist circumference measured directly by study personnel, and their body mass index calculated. Participants' current asthma symptoms were recorded by study personnel through administration of the European Community Respiratory Health Study questionnaire. ${ }^{15}$ Participants completed the standardized version of the Asthma Quality of Life Questionnaire $^{16}$ to assess their disease-specific quality of life. This questionnaire gives a score of 1 to 7 , with higher scores representing a better health status. Symptoms of gastroeophageal reflux were assessed by having the study personnel administer the Reflux Symptom Questionnaire. ${ }^{17}$

Patients then underwent lung function testing for evidence of reversible airflow obstruction (Figure 1). On the first study visit, they underwent spirometry according to the standards of the American Thoracic Society. ${ }^{18}$ Following spirometry, they received $200 \mu \mathrm{g}$ of salbutamol by pressurized metered-dose inhaler with a spacer device. Spirometry was repeated 15 minutes later. Patients whose forced expiratory volume in $1 \mathrm{sec}-$ ond $\left(\mathrm{FEV}_{1}\right)$ improved by at least $15 \%$ and at least $200 \mathrm{~mL}$ after inhalation of the bronchodilator were considered to have reversible airflow obstruction characteristic of asthma. ${ }^{19}$

Participants who did not exhibit reversible airflow obstruction returned to the pulmonary function laboratory within a week for a methacholine challenge test. They were asked not to use long-acting $\beta$-agonists for 48 hours and short-acting $\beta$ -

Table 1: Baseline characteristics of obese and nonobese study participants who had received a diagnosis of asthma from a physician (part 1)

\begin{tabular}{|c|c|c|c|}
\hline Characteristic & $\begin{array}{l}\text { Obese* } \\
n=266\end{array}$ & $\begin{array}{l}\text { Nonobese* }^{*} \\
n=274\end{array}$ & $p$ value \\
\hline Age, yr, mean (SD) & $46.9(14.0)$ & $41.5(17.4)$ & $<0.001$ \\
\hline Sex, female, no. (\%) & $175(65.8)$ & $191(69.7)$ & 0.33 \\
\hline Height, cm, mean (SD) & $166.3(9.4)$ & $167.2(9.0)$ & 0.25 \\
\hline Weight, kg, mean (SD) & $100.1(17.3)$ & $64.8 \quad(9.2)$ & $<0.001$ \\
\hline Body mass index, mean (SD) & $36.2(6.0)$ & $23.1(1.8)$ & $<0.001$ \\
\hline Waist circumference, $\mathrm{cm}$, mean (SD) & $111.8(13.4)$ & $81.5(10.3)$ & $<0.001$ \\
\hline \multicolumn{4}{|l|}{ Asthma diagnosis } \\
\hline Age at which asthma first diagnosed, yr, mean (SD) & $27.9(17.9)$ & $23.5(19.2)$ & 0.007 \\
\hline Time since asthma diagnosed, yr, mean (SD) & $19.4(13.7)$ & $18.3(14.0)$ & 0.34 \\
\hline Asthma diagnosed by family physician, no. (\%) & $178(66.9)$ & $168(61.3)$ & 0.17 \\
\hline $\begin{array}{l}\text { Asthma diagnosed by specialist (respirologist, allergist, internist or } \\
\text { pediatrician), } \dagger \text { no. }(\%)\end{array}$ & $92(34.6)$ & $108(39.4)$ & 0.25 \\
\hline \multicolumn{4}{|l|}{ Use of health care services } \\
\hline Asthma-related admission to hospital in past 12 months, no. (\%) & $2(0.8)$ & $2(0.7)$ & 0.98 \\
\hline Urgent visit to health care facility in past 12 months, no. (\%) & $45(16.9)$ & $35(12.8)$ & 0.18 \\
\hline \multicolumn{4}{|l|}{ Use of asthma medications } \\
\hline Currently using asthma medications, no. (\%) & $231(86.8)$ & $231(84.3)$ & 0.40 \\
\hline Daily use of asthma medications, no. (\%) & $115(43.2)$ & $114(41.6)$ & 0.70 \\
\hline $\begin{array}{l}\text { Daily use of inhaled corticosteroids or daily use of inhaled } \\
\text { corticosteroids / long-acting } \beta \text {-agonist combination, no. (\%) }\end{array}$ & $106(39.8)$ & $106(38.7)$ & 0.78 \\
\hline \multicolumn{4}{|l|}{ Baseline lung function } \\
\hline Forced vital capacity before bronchodilator, L, mean (SD) & $3.6(1.1)$ & $3.9(1.1)$ & $<0.001$ \\
\hline \multicolumn{4}{|l|}{$\mathrm{FEV}_{1}$, mean $(\mathrm{SD})$} \\
\hline Before bronchodilator & $2.7(0.8)$ & $2.9(0.9)$ & 0.002 \\
\hline After bronchodilator & $2.8(0.8)$ & $3.1(0.9)$ & $<0.001$ \\
\hline \multicolumn{4}{|l|}{$\mathrm{FEV}_{1}, \%$ of predicted, mean (SD) } \\
\hline Before bronchodilator & $88.1(16.5)$ & $91.4(17.9)$ & 0.02 \\
\hline After bronchodilator & $92.5(15.7)$ & $96.7(16.8)$ & 0.003 \\
\hline $\begin{array}{l}\text { Improvement in } \mathrm{FEV}_{1} \text { of } \geq 15 \% \text { and } \geq 200 \mathrm{~mL} \text { after bronchodilator, } \\
\text { no. (\%) }\end{array}$ & $24(9.1)$ & $29(10.6)$ & 0.55 \\
\hline
\end{tabular}


agonists for 8 hours before testing. The $\mathrm{FEV}_{1}$ was measured at baseline, after inhalation of aerosolized normal saline, and again after each inhalation of aerosolized saline containing methacholine in doubled doses from 0.03 to $8.0 \mathrm{mg} / \mathrm{mL}$. Participants inhaled using a Wright or Puritan-Bennett nebulizer for 2 minutes of tidal breathing with their nose clipped. $\mathrm{FEV}_{1}$ was measured at 30 seconds and at 90 seconds after each dose. Doubled concentrations of methacholine were given at 5-minute intervals until the $\mathrm{FEV}_{1}$ decreased by $20 \%$ from baseline, or until the maximum dose of methacholine was reached. Participants whose $\mathrm{FEV}_{1}$ fell by at least $20 \%$ with a methacholine dose of $8 \mathrm{mg} / \mathrm{mL}$ or less were considered to have airway hyperresponsiveness characteristic of asthma. ${ }^{14}$

Participants with an $\mathrm{FEV}_{1}$ of less than $60 \%$ of predicted, either because of fixed airflow obstruction or because of restriction related to obesity, did not undergo the methacholine challenge because of safety concerns. Instead, these patients underwent spirometry before and after bronchodilator use during the second visit. If there was still no sign of reversibility in their $\mathrm{FEV}_{1}$, we categorized them as "unable to classify."

Patients who had a negative result of the bronchial challenge test were subsequently seen by the study respiratory physician and were gradually tapered from their asthma maintenance medications (Figure 1). They were asked to halve their usual dose of inhaled corticosteroid and discontinue their antileukotriene medication. They were also asked to keep a daily symptom diary and record daily peak flow rates using a peak flow metre. They were permitted to use short- and long-acting bronchodilators as needed, but they were asked to withhold the use of long-acting $\beta$ agonists for at least 48 hours and short-acting $\beta$-agonists for 8 hours before their third study visit 2-3 weeks later.

At the third study visit, symptom assessments, spirometry and bronchial challenge testing were repeated. If participants had no acute worsening of symptoms, the spirometry showed no airflow obstruction, and the results of their bronchial challenge test were negative, they were asked to stop their inhaled corti-

Table 1: Baseline characteristics of obese and nonobese study participants who had received a diagnosis of asthma from a physician (part 2)

\begin{tabular}{|c|c|c|c|}
\hline Characteristic & $\begin{array}{l}\text { Obese* }^{*} \\
n=266\end{array}$ & $\begin{array}{l}\text { Nonobese* } \\
n=274\end{array}$ & $p$ value \\
\hline \multicolumn{4}{|c|}{$\begin{array}{l}\text { Dose of methacholine in bronchial challenge test at which } F E V_{1} \text { fell } \\
\text { by } \geq 20 \%, \neq \text { no. }(\%)\end{array}$} \\
\hline$<1 \mathrm{mg} / \mathrm{mL}$ & $72(36.4)$ & $68(32.1)$ & \multirow[t]{4}{*}{0.94} \\
\hline $1-<4 \mathrm{mg} / \mathrm{mL}$ & $29(14.6)$ & 40 (18.9) & \\
\hline $4-8 \mathrm{mg} / \mathrm{mL}$ & $13(6.6)$ & $15(7.1)$ & \\
\hline$>8 \mathrm{mg} / \mathrm{mL}$ & $84(42.4)$ & $89(42.9)$ & \\
\hline \multicolumn{4}{|l|}{ Symptoms, no. (\%) } \\
\hline Dyspnea in past 12 months & $229(86.1)$ & $215(78.5)$ & 0.02 \\
\hline Wheezing in past 12 months & $230(86.5)$ & $215(78.5)$ & 0.01 \\
\hline Current chest tightness & $67(25.2)$ & $75(27.4)$ & 0.56 \\
\hline Current cough & $130(48.9)$ & $115(42.0)$ & 0.11 \\
\hline Current dyspnea & $100(37.6)$ & $94(34.3)$ & 0.43 \\
\hline Current sputum production & $101(38.0)$ & $95(34.7)$ & 0.43 \\
\hline Current wheezing & $83(31.2)$ & $75(27.4)$ & 0.33 \\
\hline \multicolumn{4}{|c|}{ Score on Asthma Quality of Life questionnaire, $\S$ mean (SD) } \\
\hline Symptom score & $5.4(1.1)$ & $5.5(1.2)$ & 0.35 \\
\hline Activity score & $5.6(1.1)$ & $5.9(1.0)$ & $<0.001$ \\
\hline Emotion score & $5.6(1.3)$ & $5.7(1.3)$ & 0.5 \\
\hline Environmental stimuli score & $5.2(1.4)$ & $5.4(1.4)$ & 0.08 \\
\hline Total score & $5.5(1.1)$ & $5.7(1.1)$ & 0.03 \\
\hline \multicolumn{4}{|l|}{ Comorbidities } \\
\hline History of gastroesophageal reflux disease & $192(72.2)$ & $122(44.5)$ & $<0.001$ \\
\hline Gastroesophageal reflux disease occurring $\geq 1$ per week & $90(33.8)$ & $55(20.1)$ & $<0.001$ \\
\hline Diabetes mellitus & $27(10.2)$ & 7 (2.6) & $<0.001$ \\
\hline Hypertension & $68(25.6)$ & $22(8.0)$ & $<0.001$ \\
\hline
\end{tabular}

Note: $\mathrm{FEV}_{1}=$ forced expiratory volume in 1 second, SD = standard deviation

*Obese $=$ body mass index of $\geq 30$, nonobese $=$ body mass index of 20-25.

tSeveral patients reported having their asthma diagnosed by both a specialist and their family physician.

$\neq$ Results of the bronchial challenge test are reported from visit 2, before the asthma medications were tapered. Patients whose FEV ${ }_{1}$ at visit 1 improved by at least $15 \%$ after the bronchodilator, or who had a baseline $\mathrm{FEV}$, of less than $60 \%$ of predicted, did not undergo the bronchial challenge test.

$\S S$ cores of the Asthma Quality of Life Questionnaire range from 1 to 7, with higher scores indicating better asthma-specific quality of life. 
costeroid and long-acting $\beta$-agonist therapies completely and to return for a fourth study visit and bronchial challenge test 2-3 weeks later. They were asked to withhold the use of short-acting bronchodilators for at least 8 hours before this last visit.

Patients who had exacerbations of asthma symptoms during the 4-6 weeks of tapering their medications were seen by a study physician and underwent spirometry. If the study physician determined that they were having an asthma exacerbation, a diagnosis of asthma was confirmed. Patients who did not experience exacerbations of symptoms and who continued to have negative results of spirometry and bronchial challenge testing despite being off their asthma medications were classified as having normal airway responsiveness. The diagnosis of asthma was considered to have been excluded in these patients.

For patients whose diagnosis of asthma was still in doubt, an adjudication committee composed of 2 of the study physicians blinded to the patients' body mass index reviewed the study documentation for these patients. The adjudication committee did not exclude the diagnosis of asthma unless the patient had completed all of the study assessments and had successfully tapered off of his or her asthma medications without worsening of symptoms and without evidence of bronchial hyperresponsiveness. For study purposes, patients who met the above criteria met our epidemiologic definition of "absence of asthma."

All of the patients whose diagnosis of asthma was excluded were again seen by the study respiratory physician and asked to remain off their asthma medications for an additional 26 weeks. Patients were interviewed by telephone every 2 months during this period to ascertain whether they had restarted any asthma medications; whether they had had any urgent visits to a health care provider, emergency department visits or hospital admissions because of respiratory symptoms; and whether they had required any courses of oral or intravenous corticosteroid therapy for respiratory symptoms.

Table 2: Baseline characteristics of study participants whose diagnosis of asthma was confirmed or excluded after objective testing (part 1)

\begin{tabular}{|c|c|c|c|}
\hline Characteristic & $\begin{array}{l}\text { Asthma confirmed } \\
\qquad n=346\end{array}$ & $\begin{array}{l}\text { Asthma excluded } \\
\qquad n=150\end{array}$ & $p$ value \\
\hline Age, yr, mean (SD) & $44.2(16.3)$ & $44.3(15.8)$ & 0.98 \\
\hline Sex, female, no. (\%) & $240(69.4)$ & $93(62.0)$ & 0.11 \\
\hline Height, cm, mean (SD) & $166.5(9.3)$ & $168.2(8.6)$ & 0.06 \\
\hline Weight, kg, mean (SD) & $81.1(21.9)$ & $84.2(22.0)$ & 0.15 \\
\hline Body mass index, mean (SD) & $29.2(7.7)$ & $29.8(7.9)$ & 0.42 \\
\hline Waist circumference, $\mathrm{cm}$, mean (SD) & $95.5(18.8)$ & $97.7(19.8)$ & 0.25 \\
\hline \multicolumn{4}{|l|}{ Asthma diagnosis } \\
\hline Age at which asthma first diagnosed, yr, mean (SD) & $24.5(18.8)$ & $28.9(18.1)$ & 0.02 \\
\hline Time since asthma diagnosed, yr, mean (SD) & $20.1(14.2)$ & $15.5(12.4)$ & $<0.001$ \\
\hline Asthma diagnosed by family physician, no. (\%) & $221(63.9)$ & $95(63.3)$ & 0.91 \\
\hline $\begin{array}{l}\text { Asthma diagnosed by specialist (respirologist, allergist, internist or } \\
\text { pediatrician), }{ }^{*} \text { no. }(\%)\end{array}$ & $130(37.6)$ & $56(37.3)$ & 0.96 \\
\hline \multicolumn{4}{|l|}{ Use of health care services } \\
\hline Asthma-related admission to hospital in past 12 months, no. (\%) & $2(0.6)$ & $1(0.7)$ & 0.91 \\
\hline Urgent visit to health care facility in past 12 months, no. (\%) & $50(14.5)$ & $23(15.3)$ & 0.80 \\
\hline \multicolumn{4}{|l|}{ Asthma medication use } \\
\hline Currently using asthma medications, no. (\%) & $314(90.8)$ & $109(72.7)$ & $<0.001$ \\
\hline Daily use of asthma medications, no. (\%) & $170(49.1)$ & $37(24.7)$ & $<0.001$ \\
\hline $\begin{array}{l}\text { Daily use of inhaled corticosteroids or daily use of inhaled } \\
\text { corticosteroids / long-acting } \beta \text {-agonist combination, no. (\%) }\end{array}$ & $157(45.3)$ & $34(22.7)$ & $<0.001$ \\
\hline \multicolumn{4}{|l|}{ Baseline lung function } \\
\hline Forced vital capacity before bronchodilator, L, mean (SD) & $3.7(1.1)$ & $3.9(1.0)$ & 0.02 \\
\hline \multicolumn{4}{|l|}{$\mathrm{FEV}_{1}$, mean $(\mathrm{SD})$} \\
\hline Before bronchodilator & $2.7 \quad(0.8)$ & $3.1(0.8)$ & $<0.001$ \\
\hline After bronchodilator & $2.9 \quad(0.9)$ & $3.2(0.8)$ & $<0.001$ \\
\hline \multicolumn{4}{|l|}{$\mathrm{FEV}_{1}, \%$ of predicted, mean (SD) } \\
\hline Before bronchodilator & $86.4(17.3)$ & $97.1(14.8)$ & $<0.001$ \\
\hline After bronchodilator & $92.3(16.6)$ & $99.9(14.5)$ & $<0.001$ \\
\hline $\begin{array}{l}\text { Improvement in } \mathrm{FEV}_{1} \text { of } \geq 15 \% \text { and } \geq 200 \mathrm{~mL} \text { after } \\
\text { bronchodilator, no. (\%) }\end{array}$ & $54(16.3)$ & 0 & $<0.001$ \\
\hline
\end{tabular}




\section{Statistical analysis}

We calculated the sample size required to compare the rates of overdiagnosis of asthma directly in the obese and nonobese groups. Assuming an estimated prevalence of overdiagnosis of $10 \%$ in the nonobese group compared with $20 \%$ in the obese group, an $\alpha$ error of 0.05 and a $\beta$ error of 0.20 , we determined that 199 obese patients and 199 nonobese patients were required to show a $10 \%$ difference in overdiagnosis between the 2 groups.

The principal analysis was descriptive and included a measure of the prevalence of asthma overdiagnosis in each patient group, with $95 \%$ confidence intervals (CIs). We used an unadjusted $\chi^{2}$ test to compare the proportion of overdiagnosis of asthma in each of the 2 groups. We used multivariable logistic regression analysis to examine the determinants of overdiagnosis of asthma in the obese and nonobese groups, with adjustment for age, sex, level of education, baseline
$\mathrm{FEV}_{1}$, use of asthma medications before entering the study, smoking status, whether the diagnosis of asthma was made by a family physician or a specialist, presence of gastroesophageal reflux and quality-of-life score. We conducted an additional analysis to assess whether potential risk factors for misdiagnosis such as environmental exposures could also explain an incorrect diagnosis of asthma. Adjustments were made for high-risk occupation (e.g., firefighter, farmer, painter, mechanic or construction worker) and exposure to fumes, dusts, pets and cigarette smoke.

\section{Results}

A total of 75012 people were contacted by telephone through random digit dialing during the 2-year study period. Of these, 65730 answered that there was no household member older than age 16 with a diagnosis of asthma. Of the

Table 2: Baseline characteristics of study participants whose diagnosis of asthma was confirmed or excluded after objective testing (part 2)

\begin{tabular}{|c|c|c|c|}
\hline Characteristic & $\begin{array}{l}\text { Asthma confirmed } \\
\qquad n=346\end{array}$ & $\begin{array}{l}\text { Asthma excluded } \\
\qquad n=150\end{array}$ & $p$ value \\
\hline \multicolumn{4}{|l|}{$\begin{array}{l}\text { Dose of methacholine in bronchial challenge test at which FEV } \\
\text { fell by } \geq 20 \%,+ \text { no. }(\%)\end{array}$} \\
\hline$<1 \mathrm{mg} / \mathrm{mL}$ & $140(54.2)$ & 0 & \multirow[t]{4}{*}{$<0.001$} \\
\hline $1-<4 \mathrm{mg} / \mathrm{mL}$ & $69(26.7)$ & 0 & \\
\hline $4-8 \mathrm{mg} / \mathrm{mL}$ & $28(10.9)$ & 0 & \\
\hline$>8 \mathrm{mg} / \mathrm{mL}$ & $21(8.1)$ & $150(100.0)$ & \\
\hline \multicolumn{4}{|l|}{ Symptoms, no. (\%) } \\
\hline Dyspnea in past 12 months & $293(84.7)$ & $115(76.7)$ & 0.03 \\
\hline Wheezing in past 12 months & $296(85.5)$ & $112(74.7)$ & 0.004 \\
\hline Current chest tightness & $92(26.6)$ & $39(26.0)$ & 0.89 \\
\hline Current cough & $152(43.9)$ & $72(48.0)$ & 0.40 \\
\hline Current dyspnea & $130(37.6)$ & $51 \quad(34.0)$ & 0.45 \\
\hline Current sputum production & $126(36.4)$ & $55 \quad(36.7)$ & 0.96 \\
\hline Current wheezing & $105(30.3)$ & $36(24.0)$ & 0.15 \\
\hline \multicolumn{4}{|c|}{ Score on Asthma Quality of Life questionnaire, $\neq$ mean (SD) } \\
\hline Symptom score & $5.4(1.2)$ & $5.6(1.0)$ & 0.07 \\
\hline Activity score & $5.8(1.0)$ & $5.8(1.0)$ & 0.90 \\
\hline Emotion score & $5.6(1.3)$ & $5.8(1.1)$ & 0.09 \\
\hline Environmental stimuli score & $5.3(1.4)$ & $5.3(1.4)$ & 0.85 \\
\hline Total score & $5.6(1.1)$ & $5.7(1.0)$ & 0.33 \\
\hline \multicolumn{4}{|l|}{ Comorbidities } \\
\hline History of gastroesophageal reflux disease & $194(56.1)$ & $90(60.0)$ & 0.42 \\
\hline Gastroesophageal reflux disease occurring $\geq 1$ per week & $91(26.3)$ & $42(28.0)$ & 0.69 \\
\hline Diabetes mellitus & $17(4.9)$ & $11(7.3)$ & 0.28 \\
\hline Hypertension & $57(16.5)$ & $24(16.0)$ & 0.9 \\
\hline Vocal cord dysfunction & 0 & $2(1.3)$ & 0.03 \\
\hline
\end{tabular}

Note: $\mathrm{FEV}_{1}=$ forced expiratory volume in 1 second, SD = standard deviation

*Several patients reported having their asthma diagnosed both by a specialist and their family physician.

tResults of the bronchial challenge test are reported from visit 2, before the asthma medications were tapered. Patients whose FEV, at visit 1 improved by at least

$15 \%$ after the bronchodilator, or who had a baseline $\mathrm{FEV}_{1}$ of less than $60 \%$ of predicted, did not undergo the bronchial challenge test.

¥Scores of the Asthma Quality of Life Questionnaire range from 1 to 7, with higher scores indicating better asthma-specific quality of life. 
9282 potential respondents, 3156 were inaccessible or refused contact, 1654 denied a diagnosis of asthma when personally contacted, and 3931 were not eligible, either because they met one of the study exclusion criteria or declined to participate (Figure 2). Ultimately 540 individuals (266 obese and 274 nonobese) met the eligibility criteria and agreed to participate in the study.

The baseline characteristics of the obese and nonobese participants are provided in Table 1 . The mean body mass index of the obese participants was 36.2 (standard deviation [SD] 6.0), compared with 23.1 (SD 1.8) for the nonobese participants. On average, participants in both groups received their diagnosis of asthma in young adulthood; however, the obese patients were older than the nonobese patients at first diagnosis (27.9 v. 23.5 years, $p=0.007)$ and at study entry. Compared with the nonobese participants, the obese patients were more likely to report wheezing or dyspnea within the 12 months before the study; however, they did not report a higher prevalence of current asthma symptoms. Total scores and activity subscores on the Asthma Quality of Life Questionnaire were statistically lower in the obese cohort; however, the differences in mean scores did not reach the clinically important threshold of $0.5 .^{20}$ The obese patients had a higher prevalence of associated comorbidities, including gastresophageal reflux, diabetes mellitus and hypertension.

Of the 540 participants in the study, 496 (242 obese and 254 nonobese) completed all of the study assessments and could be conclusively evaluated for a diagnosis of asthma (Figure 2). Three patients in the obese group were categorized as "unable to classify" because their baseline $\mathrm{FEV}_{1}$ was less than $60 \%$ of predicted and they were unable to safely undergo a bronchial challenge test. A diagnosis of asthma was excluded in $31.8 \%$ (95\% CI 26.3\%-37.9\%) of the obese patients and $28.7 \%(95 \%$ CI $23.5 \%-34.6 \%$ ) of the nonobese patients. The difference in the rates of overdiagnosis between the 2 groups was $3.1 \%$ ( $p=$ 0.46). The unadjusted odds ratio (OR) for overdiagnosis of asthma in the obese group compared with the nonobese group was 1.19 (95\% CI $0.81-1.75, p=0.38)$. The multivariable analysis revealed similar odds of asthma overdiagnosis (adjusted OR 1.35, 95\% CI 0.85-2.11, $p=0.19$ ).

The diagnosis of asthma was confirmed in 346 of the participants: $54(16 \%)$ by means of postbronchodilator spirometry, $249(72 \%)$ by means of the bronchial challenge test, 8 (2\%) on the basis of exacerbation of asthma symptoms during the tapering off of medications, and $35(10 \%)$ through adjudication. The 35 patients whose diagnosis was confirmed through adjudication were generally those whose lung function declined and who had clinical symptoms consistent with worsening asthma during the tapering off of their medications. In these patients the diagnosis of asthma was established clinically and confirmed with spirometry rather than with repeat bronchial challenge testing.

Table 2 shows the characteristics of the 346 individuals with a confirmed diagnosis of asthma and the 150 in whom asthma was excluded. Those in whom asthma was excluded had significantly better lung function, were first diagnosed at an older age and were less likely to be using asthma medications $(72.7 \%$ v. $90.8 \%, p<0.001)$ or daily inhaled corticosteroid therapy $(22.7 \%$ v. $45.3 \%, p<0.001)$ than those with confirmed asthma. They were also slightly less likely to report dyspnea or wheezing within the 12 months before study entry. The proportions who reported current symptoms of asthma were similar in both groups. Three of the patients in whom asthma was excluded $(2.0 \%)$ had fixed airflow obstruction with an $\mathrm{FEV}_{1}$ between $60 \%-80 \%$ of predicted; however, they had no evidence of reversible airflow obstruction or bronchial hyperresponsiveness on serial testing.

The multivariable logistic regression analysis confirmed that older age at diagnosis, higher $\mathrm{FEV}_{1}$ percent of predicted, male sex, lack of daily use of asthma medications and lack of daily use of inhaled corticosteroid therapy were all significantly associated with an overdiagnosis of asthma (Figure 3). After we controlled for these covariates, obesity was still not

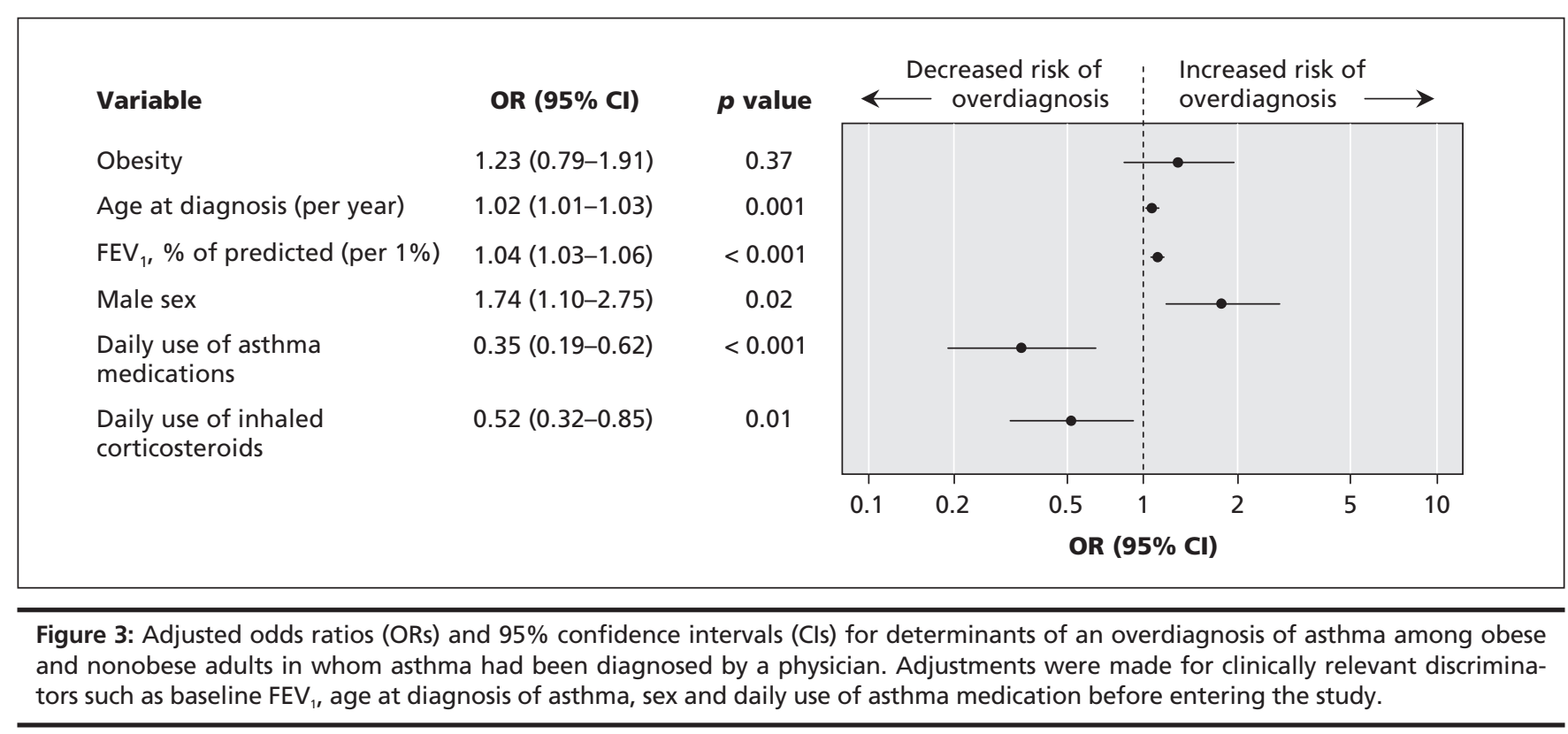


significantly associated with an overdiagnosis of asthma. We also assessed environmental exposures to fumes, dusts, pets and cigarette smoke, as well as high-risk occupations for asthma (firefighter, farmer, painter, mechanic or construction worker). Unadjusted analyses of these individual exposures did not reveal significant results. A multivariable analysis similarly showed that overdiagnosis of asthma was no more likely among people with these exposures than among those without the exposures (Figure 4).

We found that the proportion of patients who were assessed in the spring and summer months was similar in the group of patients whose asthma was excluded (56\%) and the group of those whose asthma was confirmed (53\%), excluding potential seasonal confounding effects on asthma diagnosis ( $p=0.14$ for $\chi^{2}$ test across the 4 seasons). Exclusion or confirmation of asthma was not related to highest level of education $(p=0.55)$, occupation ( $p=0.83)$, whether the diagnosis of asthma had been made by a family physician or a specialist $(p=0.91)$, or study site $(p=0.22)$.

The 150 participants in whom asthma was excluded were followed for 26 more weeks after completing their diagnostic assessment. Those using asthma medications were advised to stop taking them, and their family physician was informed that a diagnosis of asthma had been excluded. They were followed for a mean of 7.5 (SD 2.3) months from the date of their first study assessment. Eight of the participants were lost to follow-up. Of the 142 who completed the follow-up, $93(65.5 \%)$ did not need to take asthma medication and did not require health care services because of asthma symptoms. The remaining 49 (34.5\%) resumed their asthma medication during the follow-up period; 17 of them used only bronchodilators, and 12 took asthma medications for less than 14 days. Eleven of the 142 patients $(7.7 \%)$ had unscheduled visits because of respiratory symptoms: 10 saw their family physician, and 1 was seen in the emergency department. Two of these 11 patients received oral corticosteroid therapy.

\section{Interpretation}

We found that one-third of the participants who had received a diagnosis of asthma by a physician had no evidence of asthma when their medications were tapered and when they were evaluated with serial assessments of symptoms, lung function and bronchial challenge tests. One obvious interpretation of this observation is that asthma was overdiagnosed in the community. Consequently, overdiagnosis and changes in diagnostic labelling may be contributing to increases in the prevalence of asthma reported in developed countries.

An alternative possibility is that some of the adults in our study may have received an appropriate diagnosis but experienced remission of their asthma since then. Studies involving children have suggested that up to 5\% of those aged 7-12 years with asthma may experience persistent remission of their asthma (defined as absence of asthma symptoms without use of asthma medications for more than 1 year). ${ }^{21}$ However, the situation is different for adults with asthma. A Swedish study involving 300 adults from the community with physiologically confirmed asthma observed an average annual remission rate of less than $1 \%$ and an overall remission rate of only $5.8 \%$ over 10 years of follow-up. ${ }^{22}$ A second study in Sweden involving 309 adults with newly diagnosed asthma showed that, after a mean follow-up of 70 months, $95 \%$ of the patients still had active asthma (defined as the presence of asthma symptoms or use of asthma medications). ${ }^{23}$ When the authors included a methacholine challenge test to a maximum dose of $8 \mathrm{mg} / \mathrm{mL}$ to rule out asthma, as we did in our study, the rate of spontaneous remission was only $3 \%$. Thus, remission of asthma in adulthood appears to be rare and unlikely accounted for more than a small fraction of the adults in our study whose diagnosis of asthma was excluded.

A study involving Canadians without a previous diagnosis of asthma showed evidence of geographic variability in bronchial hyperresponsiveness. ${ }^{24}$ Geographic variability could theoretically account for regional differences in the rates of

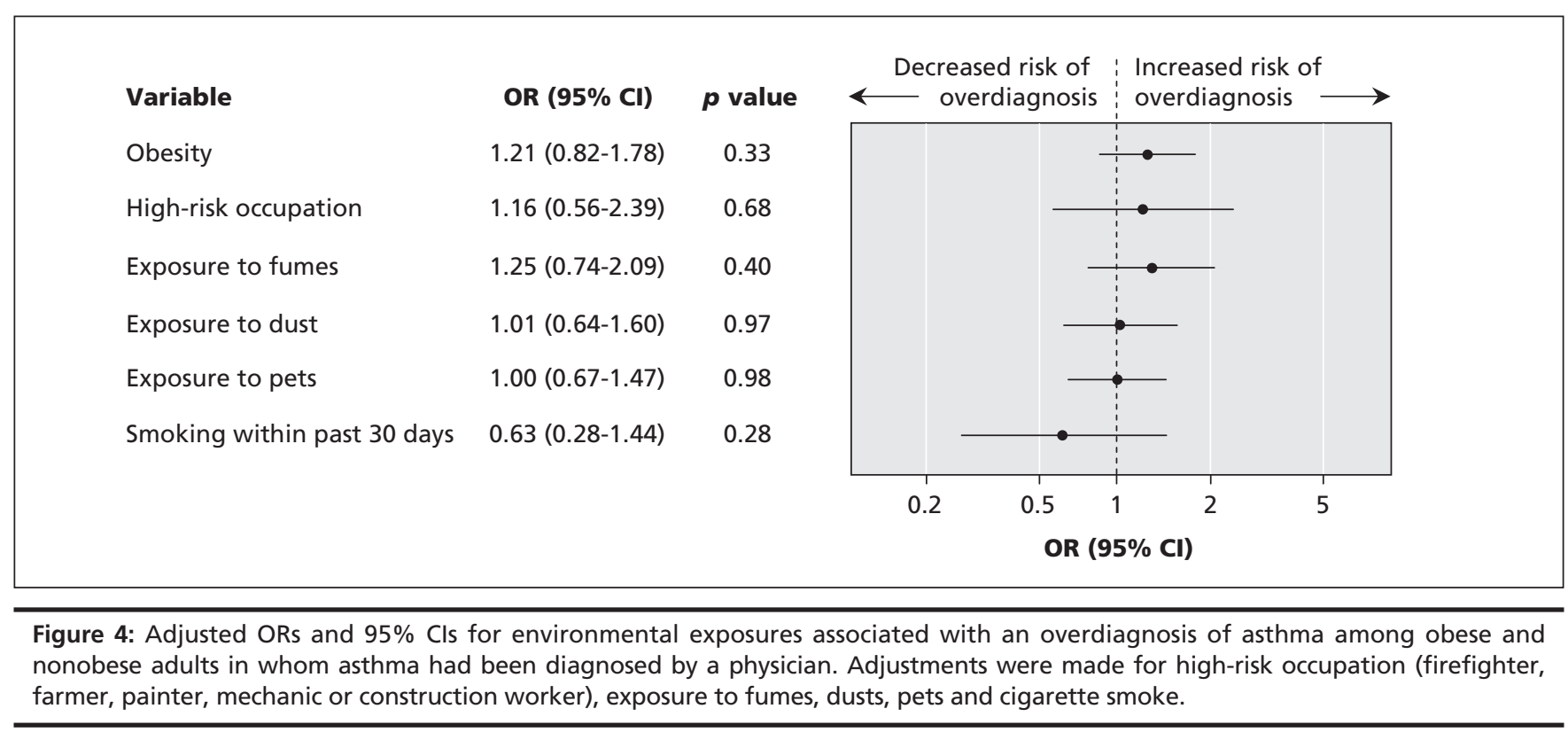


overdiagnosis of asthma. However, we found that study site was not associated with a diagnosis of asthma being confirmed or excluded ( $p=0.22$ ). Similarly, bronchial hyperresponsiveness may vary seasonally; however, we did not find any potential seasonal confounding effects on asthma diagnosis.

Short- and long-term studies have shown that the regular use of inhaled corticosteroids will result in improvements in airway hyperresponsiveness, sometimes with full resolution, and corresponding improvements in clinical status. ${ }^{25}$ Thus, when trying to exclude a diagnosis of asthma, patients need to be assessed after their anti-inflammatory medicines have been stopped. Previous studies of patients with well-controlled asthma have shown that airway hyperresponsiveness increases significantly within 20 days after discontinuation of inhaled corcitosteroid therapy. ${ }^{26}$ In our study patients were asked to taper and then stop their asthma medications over 4-6 weeks in order to remove the confounding effects of the medications on the ability to confirm a diagnosis of asthma.

We also assessed the clinical outcomes of patients who were found to have no evidence of asthma. Sixty-six percent of these patients did not need to take any asthma medications and did not seek health care services because of asthma symptoms during the 26-week follow-up period after their asthma medications had been stopped. Only 11 (7.7\%) required an unscheduled evaluation by a health care professional because of respiratory symptoms. This observation suggests that our approach to stopping medications in patients in whom asthma was excluded was safe; however, a minority of patients did experience respiratory symptoms that may or may not have been attributable to asthma.

Other studies have suggested an overdiagnosis of asthma in the community. A smaller study involving 90 self-referred individuals with asthma in Canada suggested that $41 \%$ did not have asthma when objectively tested. ${ }^{27}$ Schachter and colleagues studied adults in Australia in a cross-sectional epidemiologic study. ${ }^{28}$ They found that obesity was a significant risk factor for diagnosis of asthma (OR 2.04), wheezing and use of asthma medications (OR 2.83), but not for airway hyperresponsiveness or airflow obstruction. The authors concluded that, although individuals with severe obesity reported more symptoms consistent with asthma, their lung function tests did not support the suggestion of a higher prevalence of asthma. However, participants in their study did not stop their asthma medications before the lung function testing, which may have confounded the results.

People who are obese are more likely than nonobese people to report dyspnea. In a study involving otherwise healthy younger obese women who did not have asthma, more than $37 \%$ reported an elevated intensity of breathlessness during moderate exercise. ${ }^{11}$ Exertional dyspnea in these individuals was strongly associated with an increased oxygen cost of breathing. This may explain why obese people may report increased breathlessness with exertion, and in turn could explain why asthma is more likely to be diagnosed and treated in obese patients. However, we did not find a significant difference in the rates of overdiagnosis between the obese and nonobese participants in our study. This suggests that the increased prevalence of asthma in association with obesity that has been re- ported in previous population-based studies is a real phenomenon and not solely due to diagnostic mislabelling.

The recent rise in the prevalence of asthma in developed countries may be a consequence of patients' better education, increased awareness of symptoms and increased readiness to report them to a physician. ${ }^{29}$ In our study, more than $75 \%$ of the participants in whom asthma was eventually excluded reported dyspnea and wheezing in the 12 months before study entry. This increase in reporting of symptoms is probably occurring in concert with physicians' increased willingness to make a diagnosis of asthma in response to respiratory symptoms.

\section{Limitations}

Our study has limitations. First, many potentially eligible individuals did not agree to participate in the study. Volunteer bias could have possibly influenced the study results. Those who agreed to enroll in the study may have doubted their diagnosis of asthma in the first place, either because they had not previously undergone an extensive diagnostic workup, or because their asthma medications were not working to relieve their symptoms. If this were the case, preferential participation by these individuals may have theoretically inflated the overall proportion who were ultimately found to have no asthma.

Second, it was difficult to accurately classify patients with severe restriction due to obesity. Similarly, it was difficult to rule out asthma in participants who may have had fixed airflow obstruction. Three obese participants could not be classified because they had severe restrictive defects and an $\mathrm{FEV}_{1}$ less than $60 \%$ of predicted. In addition, 3 of the 150 participants in whom asthma was excluded did have fixed airflow obstruction. These 3 individuals may have been misclassified.

\section{Conclusion}

There are obvious consequences associated with a misdiagnosis of asthma, including the lost opportunity to investigate or treat the cause of the patient's respiratory symptoms appropriately, the patient's potential exposure to the adverse effects of asthma medications, the cost of asthma medications, and the social consequences and psychological impact on the patient of being labelled with a chronic respiratory disease. Our study showed that a substantial proportion of people, whether obese or not, may be overdiagnosed with asthma and may be prescribed asthma medications unnecessarily. Physicians should consider objective testing using spirometry and, if necessary, bronchial challenge testing to confirm asthma in patients with respiratory symptoms.

\section{This article has been peer reviewed.}

Competing interests: Shawn Aaron is an advisory board member for AstraZeneca, Boerhinger-Ingelheim, GlaxoSmithKline and Talecris. LouisPhilippe Boulet has served as an advisory board member for AstraZeneca, GlaxoSmithKline, Novartis and Schering-Plough. He has received speaker fees from Altana, AstraZeneca, GlaxoSmithKline, Merck Frosst, Novartis and MedImmune; research funding from AstraZeneca, GlaxoSmithKline, Merck Frosst, Novartis, Schering-Plough, Alexion, AsthmaTx, BoehringerIngelheim, Ception, Genentech, IVAX, MedImmune, Topigen and Wyeth; and support for the production of educational materials and initiatives from AstraZeneca, GlaxoSmithKline and Merck Frosst. Andrew McIvor has re- 
ceived honoraria for continuing medical education and for attending advisory boards from AstraZeneca, Boehringer-Ingelheim, GlaxoSmithKline, Novartis, Nycomed, Merck and Graceway. Paul Hernandez has received speaker fees and educational grants from Actelion, AstraZeneca, BoehringerIngelheim, GlaxoSmithKline and Pfizer; and consultancy fees from Actelion, Altana, AstraZeneca, Boehringer-Ingelheim, GlaxoSmithKline, Nycomed and Pfizer. No competing interests declared for Katherine Vandemheen, Mark FitzGerald, Catherine Lemiere, Sat Sharma, Stephen Field, Gonzalo Alvarez, Robert Dales, Steve Doucette or Dean Fergusson.

Contributors: Shawn Aaron had full access to all of the data in the study and takes responsibility for the integrity of the data and the accuracy of the data analysis. Shawn Aaron, Katherine Vandemheen, Paul Hernandez, Robert Dales and Dean Fergusson were responsible for the study concept and design. Data were acquired by Shawn Aaron, Katherine Vandemheen, Louis-Philippe Boulet, Andrew McIvor, Mark FitzGerald, Paul Hernandez, Catherine Lemiere, Sat Sharma, Stephen Field and Gonzalo Alvarez. Shawn Aaron, Katherine Vandemheen, Steve Doucette and Dean Fergusson were responsible for the analysis and interpretation of the data. Shawn Aaron drafted the manuscript; the other authors revised the manuscript critically for important intellectual content. Funding was obtained by Shawn Aaron, Katherine Vandemheen, Mark FitzGerald, Catherine Lemiere, Robert Dales and Dean Fergusson. Shawn Aaron, Katherine Vandemheen, Louis-Philippe Boulet, Andrew McIvor, Mark FitzGerald, Paul Hernandez, Catherine Lemiere, Sat Sharma, Stephen Field, Gonzalo Alvarez and Robert Dales acted as study supervisors. No medical writer was involved in drafting or editing this manuscript. All of the authors approved the final manuscript submitted for publication.

Acknowledgments: We thank the following people for their invaluable assistance. Study coordinators: Kim Danovitch, Karen Seal, Hélène Turcotte, Sarah Goodwin, Suju Mathew, Sherie Keogh, Linda Hui, Scott Fulton, Carole Trudeau, Nimisha Purohit, Noreen Garanhel, Nicole Marten, Jimmy Joy, Linda Sayler and Diane Conley. Data managers: My-Linh Tran and Jennie Cote. We also thank Methapharm Inc., Brantford, Ont., for supplying the methaocholine for the bronchial challenge testing; Trudell Medical International Inc., London, Ont., for supplying the peak flow metres; Respironics Inc., Oakville, Ont., for supplying the Optichamber Advantage spacer devices; and ASDE Survey Sampler Inc., Gatineau, Que., for coordinating the random-digit dialing.

Funding: This study was funded by the Canadian Institutes of Health Research (grant no. MOP-77520) and the Division of Respiratory Medicine, The Ottawa Hospital. None of the sponsors or funders had any involvement in the design or conduct of the study; the collection, management, analysis or interpretation of the data; or the preparation, review or approval of the manuscript.

\section{REFERENCES}

1. National Center for Health Statistics. Vital statistics of the United States, 1999. Hyattsville (MD): US Department for Health and Human Services; 1999.

2. Canadian Institute for Health Information. Respiratory disease in Canada. Ottawa (ON): The Institute; 2001. p. 45-55.

3. Eder W, Ege MJ, von Mutius E. The Asthma Epidemic. N Engl J Med 2006; 355:2226-35

4. Devenny A, Wassall H, Ninan T, et al. Respiratory symptoms and atopy in children in Aberdeen: questionaire studies of a defined school population repeated over 35 years. BMJ 2004;329:489-90.

5. Chinn S. Asthma and obesity: Where are we now? Thorax 2003;58:1008-10.

6. Camargo CA Jr, Weiss ST, Zhang S, et al. Prospective study of body mass index, weight change, and risk of adult-onset asthma in women. Arch Intern Med 1999; 159:2582-8

7. Boulet LP, Des Cormiers A. The link between obesity and asthma: a Canadian perspective. Can Respir J 2007;14:217-20.

8. Sin DD, Jones RL, Man SF. Obesity is a risk factor for dyspnea but not for airflow obstruction. Arch Intern Med 2002;162:1477-81.

9. Chen Y, Dales R, Krewski D, et al. Increased effects of smoking and obesity on asthma among female Canadians: the National Population Health Survey, 1994-1995. Am J Epidemiol 1999;150:255-62.
10. Sharp JT, Henry JP, Sweany SK, et al. The total work of breathing in normal and obese men. J Clin Invest 1964;43:728-39.

11. Babb TG, Ranasinghe KG, Comeau LA, et al. Dyspnea on exertion in obese women: association with an increased oxygen cost of breathing. Am J Respir Crit Care Med 2008;178:116-23

12. Aaron SD, Fergusson D, Dent R, et al. Effect of weight reduction on respiratory function and airway reactivity in obese women. Chest 2004;125:2046-52.

13. Hartge P, Brinton L, Rosenthal J, et al. Random digit dialing in selecting a population-based control group. Am J Epidemiol 1984;120:825-33.

14. American Thoracic Society. Guidelines for methacholine and exercise challenge testing. Am J Respir Crit Care Med 2000;161:309-29.

15. Variations in the prevalence of respiratory symptoms, self-reported asthma attacks, and use of asthma medication in the European Community Respiratory Health Survey. Eur Respir J 1996;9:687-95.

16. Juniper EF, Buist AS, Cox FM, et al. Validation of a standardized version of the Asthma Quality of Life Questionnaire. Chest 1999;115:1265-70.

17. Dauer E, Thompson D, Zinmeister AR, et al. Supraesophageal reflux: validation of a symptom questionnaire. Otolaryngol Head Neck Surg 2006;134:73-80.

18. American Thoracic Society. Standardization of spirometry - 1987 update. Statement of the American Thoracic Society. Am Rev Respir Dis 1987;136:1285-98.

19. Boulet LP, Becker A, Bérubé D, et al. Canadian Asthma consensus report, 1999. CMAJ 1999;161(Suppl 11):S1-62.

20. Juniper EF, Guyatt GH, Willan A, et al. Determining a minimal important change in a disease-specific quality of life questionnaire. J Clin Epidemiol 1994;47:81-7.

21. Bjerg-Bäcklund A, Perzanowski MS, Platts-Mills TAE, et al. Asthma during the primary school ages - prevalence, remission and the impact of allergic sensitization. Allergy 2008;61:549-55.

22. Ronmark E, Jonsson E, Lundback B. Remission of asthma in middle-aged and elderly-report from the Obstructive Lung Disease in Northern Sweden Study. Thorax 1999;54:611-3.

23. Ronmark E, Lindberg A, Watson L, et al. Outcome of severity of adult onset asthma - report from the Obstructive Lung Disease in Northern Sweden Studies. Respir Med 2007;101:2370-7.

24. Manfreda J, Sears MR, Becklake MR, et al. Geographic and gender variability in the prevalence of bronchial responsiveness in Canada. Chest 2004;125:1657-64

25. Juniper EF, Kline PA, Vanzieleghem MA, et al. Effect of long-term treatment with an inhaled corticosteroid (Budesonide) on airway hyperresponsiveness and clinical asthma in nonsteroid-dependent asthmatics. Am Rev Respir Dis 1990;142:832-6.

26. Marabini A, Cardinalini G, Severini C, et al. Is normal bronchial responsiveness in asthmatics a reliable index for withdrawing inhaled corticosteroid treatment? Chest 1998;113:964-7.

27. Linden-Smith J. Morrison D, Deveau C, et al. Overdiagnosis of asthma in the community. Can Respir J 2004;11:111-6.

28. Schachter LM, Salome CM, Peat JK, et al. Obesity is a risk for asthma and wheeze but not airway hyper-responsiveness. Thorax 2001;56:4-8.

29. Barraclough R, Devereux G, Hendrick DJ, et al. Apparent but not real increase in asthma prevalence during the 1990s. Eur Respir J 2002;20:826-33.

Correspondence to: Dr. Shawn Aaron, Division of Respiratory Medicine, Department of Medicine, The Ottawa Hospital - General Campus, 501 Smyth Rd., Ottawa ON K1H 8L6; fax 613 739-6266; saaron@ohri.ca

Members of the Steering Committee of the Canadian Respiratory Clinical Research Consortium: Dr. Shawn Aaron, University of Ottawa, Ottawa, Ont.; Dr. Louis-Philippe Boulet, Université Laval, Québec, Que.; Dr. Jean Bourbeau, McGill University, Montréal, Que.; Dr. Penny Brasher, University of British Columbia, Vancouver, BC; Dr. Dina Brooks, University of Toronto, Toronto, Ont.; Dr. Lisa Cicutto, University of Colorado, Denver, USA; Dr. Rajashree Devarakonda, University of British Columbia, Vancouver, BC; Dr. Mark Fitzgerald, University of British Columbia, Vancouver, BC; Dr. John Fleetham, University of British Columbia, Vancouver, BC; Dr. Catherine Lemiere, Université de Montréal, Montréal, Que.; Dr. Brian Rowe, University of Alberta, Edmonton, Alta.; and Ms. Katherine Vandemheen, Ottawa Health Research Institute, Ottawa, Ont. 